\title{
Lebenslauf Prof. Dr. Susanna Bliggenstorfer
}

geb. 20. Dezember 1953 in Zürich

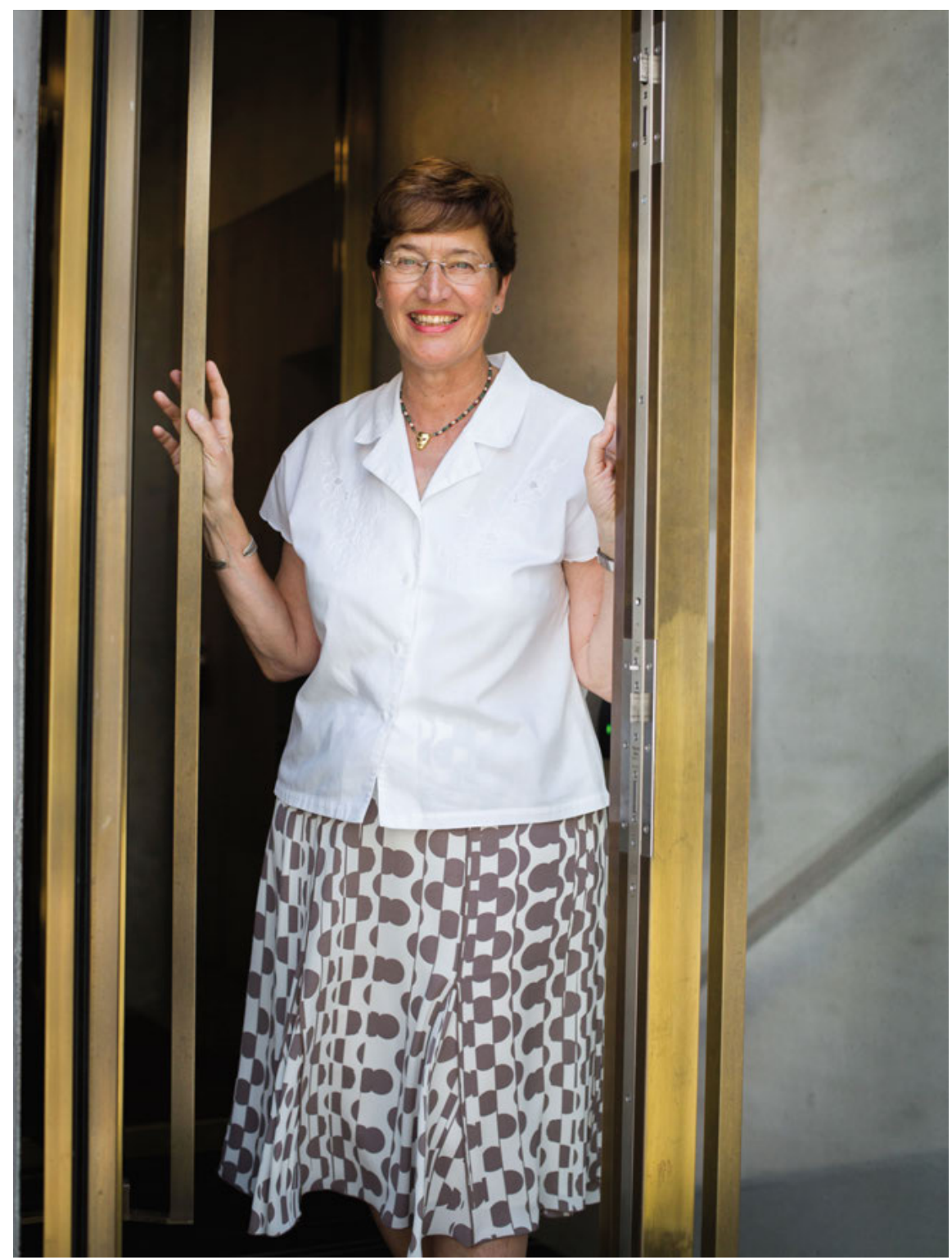

(c) Anne Gabriel-Jürgens, ursprünglich erschienen in: NZZ Folio „Bibliotheken“ Nr. 313 (2017) 


\section{Ausbildung}

1960-74 Primar- und Sekundarschule in Dietlikon (ZH), Pensionnat de jeunes filles „Iréna“ in Neuchâtel, Höhere Töchterschule Hottingen in Zürich (Abschluss: Handelsdiplom) und Kantonschule Enge in Zürich (Matur Typus E, Wirtschaftsmatur)

1974-1980 Studium an der Philosophischen Fakultät der Universität Zürich: Französische Sprache und Literatur, Italienische Literatur und Rätoromanische Sprache und Literatur

1980-1981 Forschungsaufenthalt in Paris

1987 Promotion an der Philosophischen Fakultät der Universität Zürich. Titel der Dissertation George Chastelain. Le Temple de Bocace. Edition commentée

2000 Habilitation an der Universität Zürich, Erteilung der venia legendi für das Gebiet der Romanischen Philologie unter besonderer Berücksichtigung der älteren galloromanischen und italienischen Literatur. Titel der Habilitationsschrift Eustache Deschamps, aspects poétiques et satiriques

$2007 \quad$ Ernennung zur Titularprofessorin

\section{Berufliche Tätigkeiten}

1981-1986 Assistenz bei Prof. Dr. Marc-René Jung, Romanisches Seminar der Universität Zürich

1988-2004 Stabsleiterin des Prorektorats Geistes- und Sozialwissenschaften (bis 1998 Prorektorat Lehre und Forschung, dann Prorektorat Lehre)

2004-2005 Vizedirektorin der Stadt- und Universitätsbibliothek Bern

2005-2008 Direktorin der Stadt- und Universitätsbibliothek Bern (ab Januar 2007 Universitätsbibliothek Bern)

2008-2017 Direktorin der Zentralbibliothek Zürich verschiedene Lehrtätigkeiten an der Universität Zürich im Fach Romanistik sowie im Bereich Bibliotheks- und Informationswissenschaft in Zürich und Bern 


\section{Mitarbeit in Kommissionen und Gremien in Auswahl}

- Lenkungsausschuss und Studiengangleitung des universitären Weiterbildungsstudiengangs für Bibliotheks- und Informationswissenschaft in Kooperation mit der Philosophischen Fakultät der Universität Zürich

- Konferenz der Universitätsbibliotheken der Schweiz (KUB): Präsidium von 2012-2016

- Konferenz der Deutschschweizer Hochschulbibliotheken (KDH)

- Steuerungsausschuss des Programms SUK P-2 „Wissenschaftliche Information: Zugang, Verarbeitung und Speicherung“ (projektgebundene Beiträge des Bundes 2013-2016)

- Steuerungsausschuss des Projektes Swiss Library Service Platform (SLSP)

- Speicherbibliothek AG

- NEBIS-Steuerungsgremium, Mitglied und Vorsitzende

- SAGW-Kommission eines Daten- und Dienstleistungszentrum für geisteswissenschaftliche Forschungsdaten (Vorgänger von DaSCH)

- Lenkungsausschuss von e-lib.ch: Elektronische Bibliothek Schweiz (projektgebundene Beiträge des Bundes 2008-2012)

- Bibliothekskommission der Universität Zürich

- Schweizerische Bibliophile Gesellschaft, Vorstand

- Museumsgesellschaft Zürich, Vorstand

- Alfred Escher-Stiftung, Vorstand

- Forschungsstiftung Johann Caspar Lavater, Stiftungsrat 
